\title{
Tertulias Dialógicas en el Grado de Magisterio
}

Daniel Gabaldón Estevan ${ }^{a}$, Sandra Obiol I Francés ${ }^{b}$ Jose Beltran Llavador $^{c}$ y Antonio Benedito Casanova ${ }^{d}$

${ }^{a}$ Universitat de València Daniel.Gabaldon@uv.es, ${ }^{b}$ Universitat de València Sandra.Obiol@uv.es, 'Universitat de València Jose.Besltram@uv.es y Universitat de València Antonio.Benedito@uv.es.

\begin{abstract}
We are aware that overcoming educational challenges that the "traditional" university faces requieres a renewal of teaching methodologies. Without losing sight of the objectives, it has to be able to articulate more dynamic and participatory dynamics of teaching and learning where the active role of students becomes relevant while also protagonist of their own learning and in which the teacher must combine, more often than before, different dynamics and teaching strategies. In this context of change, framed in educational innovation projects and improved teaching quality initiatives like the one we present here, we seek to help rethink classroom work. The aim of this paper is to present an innovative experience carried out in three subjects, Social Structure and Education and Sociology of Education first and second year respectively, in the Teacher education Bachelor degree, and the Bachelor degree of Sociology at the University of Valencia.
\end{abstract}

Keywords: dialogic literary circle, participation,

\section{Resumen}

Conscientes de que la superación de los retos pedagógicos a los que se enfrenta la universidad "tradicional" pasa por una renovación de las metodologías docentes que, sin perder de vista los objetivos marcados, sea capaz de articular dinámicas de enseñanza-aprendizaje más dinámicos y participativos dónde el papel activo del alumnado cobra relevancia en tanto que protagonista de su propio aprendizaje y en el que lalel docente deberá combinar, más a menudo que hasta ahora, diferentes dinámicas y estrategias docentes. En este contexto de cambio, y enmarcadas en la innovación educativa y los proyectos de mejora de la calidad docente, surgen iniciativas como la presente que buscan replantear el trabajo en el aula. El objetivo de este artículo es presentar una experiencia innovadora llevada a cabo en tres asignaturas, Estructura Social y Educación, y Sociología de la Educación de primero y segundo curso respectivamente, del Grado en Maestro/a en Educación Infantil y del Grado en Maestro/a en Educación Primaria, y de la titulación de Sociología de la Universitat de València.

Palabras clave: tertulias literarias dialógicas, participación 


\section{Introducción}

La tertulia dialógica es una experiencia de éxito que se deriva de la metodología comunicativa crítica, y trata de modificar tanto la calidad, la cantidad, como los actores implicados en las interacciones en el aula, dando más peso a la interacción del alunado entre sí y con el profesorado, todo ello con la finalidad de propiciar una mayor implicación y motivación, mejorar el desarrollo de competencias, y conseguir una mejor y más duradera adquisición de conocimientos por parte del alumnado. Fundamentada en las aportaciones seminales de Lev Vygotski, con su idea de que si se aprende a pensar en grupo, luego se sabrá pensar mejor en solitario, la metodología comunicativa crítica pretende el replanteamiento de pedagogías obsoletas con la finalidad de propiciar una mayor implicación y motivación, mejorar el desarrollo de competencias, y conseguir una mejor y más duradera adquisición de conocimientos por parte del alumnado. En palabras de Freire $(2012,63-64)$

"Este punto nos lleva a la necesidad de la lectura también como experiencia dialógica, en la que la discusión del texto realizada por sujetos lectores aclara, ilumina y crea la comprensión grupal de lo leído. En el fondo, la lectura en grupo hace emerger diferentes puntos de vista que, exponiéndose los unos a los otros, enriquecen la producción de la inteligencia del texto.

Entre las mejores prácticas de lectura que he tenido dentro y fuera de Brasil yo citaría las que realicé coordinando grupos de lectura sobre un texto.

Lo que he observado es que la timidez frente a la lectura o el propio miedo tienden a ser superados y se liberan los intentos de invención del sentido del texto y no sólo de su descubrimiento."

En nuestro contexto educativo, la mayoría de iniciativas reportadas que incluyen tertulias dialógicas y grupos interactivos se centran en aulas de educación primaria, y frecuentemente también se refieren a Centros compensatorios de Acción Educativa Especial y Centros de Acción Educativa Singular (CAES), pero poco ha trascendido sobre su aplicación a otros niveles educativos, en especial en el ámbito universitario.

El objetivo de este artículo es presentar una experiencia innovadora ${ }^{1}$ llevada a cabo en tres asignaturas, Estructura Social y Educación, y Sociología de la Educación de primero y segundo curso respectivamente, del Grado en Maestro/a en Educación Infantil y del Grado en Maestro/a en Educación Primaria, y de la titulación de Sociología de la Universitat de València.

Esta experiencia de innovación educativa responde a una multiplicidad de objetivos:

1. Pretendíamos recuperar de algún modo la práctica de los seminarios de investigación, que hasta el momento no ha disfrutado de una implantación institucional en nuestras Universidades Públicas. Tomando como hilo conductor la lectura y el estudio profundo de una obra, se trataba de pensar sobre ella y poner en común nuestras reflexiones en un

\footnotetext{
1 Este trabajo, Tertulias Dialógicas en el Grado de Magisterio (TeDiGraMa) UV-SFPIE_RMD15-314917 cuenta con autorización del Vicerectorat de Polítiques de Formació i Qualitat Educativa de la Universitat de València.
}

(cc) EY-NC-ND 2016, Universitat Politècnica de València 
formato de seminario, es decir, de participación colectiva. Con este formato se pretende fomentar la figura del maestro/profesor como intelectual (Giroux, 1990), que lleva a cabo en su práctica docente un trabajo específicamente intelectual, es decir, de problematización, de objetivación y de reflexión en relación con la sociedad histórica en que vivimos.

2. Para potenciar el objetivo de cualquier proceso de investigación científica que consiste en lograr la comprensión de la realidad a partir de la modelización de su inteligibilidad y siguiendo las valiosas aportaciones de Wagensberg (2007) en esta línea, hemos otorgado una centralidad al momento de la "conversación" como medio preferente para llegar a esa comprensión. Puesto que el proceso conversacional tiene tres modalidades (conversación con uno mismo, con los otros y con la realidad), hemos secuenciado la actividad de la tertulia dialógica como una puesta en relación del libro con la realidad, la escritura en forma de preguntas de nuestras reflexiones y, por último, "el grupo de discusión" grabado sobre la obra.

3. Entendemos que este tipo de prácticas innovadoras adquieren su sentido específico en un proceso actual de desinstitucionalización (Dubet, 2013) de nuestras universidades, en las que la acción dominante por parte de los estudiantes es "competir" y "adaptarse" a unas reglas impuestas que, precisamente, no posibilitan la adquisición de un aprendizaje profundo, el cual tiene que ver más con la formulación de preguntas (Bain, 2007; 2014) que con la memorización de respuestas en formato "power point".

4. Somos conscientes de los antecedentes múltiples de este enfoque. La importancia de la dialogicidad y de trabajar para la producción de sujetos autónomos tiene como referente a P.Freire. La distinción entre una escuela democrática que atienda más a la formación que a la clasificación de los estudiantes y una escuela credencialista cada vez reducida a mera organización de las personas y de los saberes o a mera fabricación de diplomas, tiene que mirar hacia los trabajos de Anaya (1977) y de Chomsky (2010).

5. Por otra parte, desde el campo de la sociología de la educación (Martin, 2010) no podemos dejar de considerar estas prácticas educativas como una de las posibilidades que el campo escolar ofrece, de forma que no pueda ser considerado como un espacio exclusivo de determinación social. Se trata, más bien, de un espacio social y político que, aunque esté vinculado con el campo del poder y con la dinámica de la estructura social, en él se juegan jugadas que trascienden los límites del campo y van en la dirección de la transformación social (Ardoino, 1980).

6. Trabajar en la línea de la transferencia social del conocimiento científico y educativo (Cordón, 1982) y en la línea "sociológica" de contribuir a una educación centrada en la "comprensión" (Morin, 2001) es lo que ha movido el equipo a diseñar esta "compleja" experiencia de innovación docente educativa, aplicable al Grado de Magisterio y al de Sociología.

\section{Objetivos}

El proyecto de innovación del que se nutre esta comunicación consiste en la celebración de tertulias dialógicas con grupos reducidos entorno a la lectura de un libro acordado. Al finalizar la actividad el alumnado cumplimenta un cuestionario para valorar el grado de

(cc) EY-NC-ND 2016, Universitat Politècnica de València

Congreso In-Red (2016) 
satisfacción con la actividad realizada, así como otros aspectos sobre su funcionamiento y mejora (ver anexo).

Opcionalmente, cuando el profesorado lo ha encontrado factible, las sesiones se han realizado en las instalaciones del Social-lab, el laboratorio de ciencias sociales de la Facultat de Ciencies Socials de la UV.

El germen de esta experiencia innovadora se ha gestado en el curso anterior 2014/2015 cuando en el marco de las actividades del curso se han celebrado tertulias dialógicas en grupos reducidos, entorno a la lectura de un libro acordado, en este caso Mal de escuela de Daniel Pennac (2012). El alumnado de dos grupos pudo optar por leer el libro como una de las actividades evaluables para las asignaturas de Estructura Social y Educación (1er curso) y Sociología de la Educación (2do curso) y la participación en las tertulias fue voluntaria. Para facilitar el análisis de las tertulias estas fueron grabadas haciendo uso de las instalaciones del Social-lab, laboratorio de ciencias sociales de la Facultat de Ciencies Socials de la UV. La buena acogida y buena valoración de la actividad por parte del alumnado nos ha animado a conformarla como un proyecto de innovación

\section{Desarrollo de la innovación}

El alumnado podía optar por leer entre uno o dos libros como una de las actividades evaluables para las asignaturas, siendo la participación en las tertulias también voluntaria. Las tertulias se realizan en las instalaciones del Social lab, el laboratorio de ciencias sociales de la Facultat de Ciencies Socials de la UV.

Por último, para obtener una retroalimentación de la actividad se desarrolló un cuestionario a partir del trabajo de Requero y Yuste (2013), que se puede ver en el anexo 1, y de cuyo análisis mediante SPSS permite extraer los datos sobre la evaluación de la actividad por parte del alumnado.

\subsection{Lecturas seleccionadas}

El planteamiento de la actividad consiste en la celebración de tertulias dialógicas en grupos reducidos de alumnas y alumnos, entorno a la lectura de los siguientes libros:

\subsubsection{Adorno, T. y Horkheimer, M. Dialéctica de la ilustración. Madrid: Akal, 2007.}

En el segundo curso del Grado de Sociología se imparte la materia anual ( 9 créditos) de "La tradición sociológica, y este ensayo publicado en 1947 por T.Adorno y M.Horkheimer, investigadores sociales de la primera generación de la denominada "Escuela de Frankfurt", es el producto de una reflexión colectiva llevada a cabo en el exilio (EEUU) durante la Segunda Guerra Mundial. Ante los fenómenos socio-históricos del triunfo del nazismo y el estallido de un nuevo conflicto bélico total, estos autores, en una profunda conversación, se preguntan "por qué la humanidad, en lugar de alcanzar un estado verdaderamente humano, se hunde en una nueva forma de barbarie". Ante la detención y el fracaso de la práctica social transformadora (experiencia soviética) y la reducción del pensamiento a un ejercicio positivista que acepta, sin cuestionar, lo real tal y como se presenta, la obra se plantea trabajar esa otra dimensión del ejercicio de pensar consistente en construir mediaciones/relaciones en el conocimiento de lo social y en poder reflexionar sobre los

(cc) BY-NC-ND 2016, Universitat Politècnica de València 
procesos ilustrados de reflexión para poder decir "no" a lo real mismo. Con ese fin llevan a cabo una genealogía y una problematización de la forma subjetiva e instrumental de la racionalidad.

Tras examinar cómo y por qué la ilustración recae en el mito, después de surgir de una crítica al mismo, se nos presenta una profundización del concepto de ideología, tal y como había sido elaborado por K.Marx, con el fin de entender de qué modo la civilización ha terminado por caer a prácticas de barbarie. Dada la importancia que tiene la obra seleccionada para el desarrollo posterior de la teoría sociológica contemporánea y no solamente para la historia propia de la Escuela de Frankfurt y teniendo en cuenta que se trata de un ensayo de reflexión vinculado al desenvolvimiento de nuestra cultura occidental, me ha parecido que, a pesar de la dificultad, era una pieza formativa esencial. Por otra parte, la obra nos sitúa directamente en el análisis de nuestro presente al examinar la importancia que los medios de comunicación de masas tienen para la construcción de las formas de pensar y para las transformaciones sociales del capitalismo y del liberalismo. De hecho, los estudiantes han centrado sus reflexiones en el papel que están jugando estos medios de comunicación (la industria cultural) en nuestras vidas.

1.1.2. Bergala, A., Aidelman, N., y Colell, L. (2007). La hipótesis del cine: pequeño tratado sobre la transmisión del cine en la escuela y fuera de ella. Laertes.

Con esta obra, el crítico y experto en cine Alain Bergala sostiene la necesidad de introducir el cine en las escuelas como herramienta de conocimiento. A través de una serie de capítulos que narran su experiencia cultural, Bergala defiende la hipótesis de la importancia creciente del cine para las nuevas generaciones de escolares, nacidos como nativos digitales, y educados en un entorno donde el formato audiovisual forma parte de su entorno cotidiano. La lectura de esta obra se complementa con otra obra colectiva, Didáctica de la pantalla, que a su vez es el resultado de otro proyecto anterior de innovación educativa llevado a cabo en la Facultad de Magisterio desde hace casi diez años (puede consultarse la página web...). El interés de esta obra, en este sentido, es doble: por el elevado interés de su contenido, con el que el estudiantado se identifica muy directamente, y por entrar en conexión con otro tipo de innovación educativa en el que participa un nutrido grupo de docentes de la Facultad de Magisterio, favoreciendo de este modo una sinergia muy enriquecedora entre ambos proyectos.

\subsubsection{Ferrer i Guàrdia, F. (1976). La escuela moderna. Madrid: Júcar}

Esta obra de Ferrer i Guardia, que ya tiene más de cien años, constituye sin duda una de las obras principales de la escuela nueva, y no ha pérdido un ápice de vigencia. Su autor fue, además de un sólido y librepensador, un pedagogo original y visionario, cuya propuesta educativa se adelantó a su propia época. Con esta obra, Ferrer i Guardia presenta, de manera directa, clara y estimulante, algunos de los elementos clave que hoy podemos identificar como "innovación educativa": creatividad combinada con compromiso, metodologías activas al servicio de un aprendizaje colaborativo. Con esta obra, los estudiantes pueden asomarse a alguno de los precedentes de nuestras reformas educativas y

(cc) EY-NC-ND 2016, Universitat Politècnica de València

Congreso In-Red (2016) 
al mismo tiempo se aproximan a la perspectiva histórica al servicio de la comprensión sociológica.

\subsubsection{Freire, P. (2012). Cartas a quien pretende enseñar. Madrid: Biblioteca Nueva.}

Esta obra de Paulo Freire, escrita en 1993, es una de sus últimas reflexiones y supone una síntesis de su extensa obra al tiempo que un legado para las generaciones de futuros maestros. En la unidad docente de Sociología de la Educación se recomendó a la Facultad de Magisterio que ningún estudiante de Grado de Maestro en Educación Infantil o en Educación Primaria debería acabar sus estudios sin haber leído al menos una obra del pedagogo brasileño. A través de diez cartas, Paulo Freire revisa sus principales contextos y de nuevo enfatiza la importancia de una relación diálogica en el proceso de enseñanza y aprendizaje. El diálogo fundamentó el desarrollo del pensamiento occidental desde su orígenes y dio sentido a la paideia como herramienta de conocimiento desde un punto de vista individual y colectivo. Freire consideraba que el diálogo es el vehículo que permite el paso del texto al contexto, de la lectua de la palabra a la lectura de la realidad. En buena medida, los principios metodológicos de las tertulias dialógicas se han inspirado en la perspectiva educativa y epistemológica de Paulo Freire.

\subsubsection{Pennac, D. (2012). Mal de escuela. Barcelona: Mandadori.}

Esta novela, del prestigioso escritor francés Daniel Pennac, tiene un marcado carácter autobiográfico, y narra su propia experiencia como estudiante fracasado en un tramo de su escolarización, que es capaz de superar tanto sus dificultades como el estigma del fracaso, precisamente acudiendo, entre otras herramientas, al poder de la lectura. Una tesis que había defendido en una obra anterior, de carácter ensayístico, titulada Como una novela, y convertida en un bestseller y en un libro de referencia para estudiantes, educadores, intelectuales y gente de la cultura en general. En ambas obras, Daniel Pennac muestra la importancia de entrar en diálogo tanto con los autores como con los personajes y situaciones que nos presentan los libros más variopintos. Al hablar en primera persona, los estudiantes son capaces de empatizar, reconocer y proyectarse en las experiencias educativas que narra el autor. En realidad, lo que hace el autor en esta obra es una variación interesante de lo que Ivor Goodson denomina "aprendizaje narrativo" y Peter Alheit caracteriza como "biograficidad", ambas formando parte de la importante vinculación entre educación y biografías (Hernàndez y Villar, 2015).

\subsubsection{Ravitch, D. (2013) Reign of error: The hoax of the privatization movement and the danger to America's public schools. Vintage.}

El libro es de Diana Ravitch, la que fuera una de las principales responsables de implementar las políticas educativas en EEUU durante las presidencias de Bush y Clinton, como la famosa y ahora denostada No Child Left Behind, y su énfasis en el "accountability" (el uso sistemático de evaluaciones que miden la "calidad" educativa). En él, la autora revisa críticamente la implementación de las políticas que han llevado a los EEUU a apostar por las “charter schools"en detrimento de la enseñanza pública. 


\subsubsection{Sahlberg, P. (2014) Finnish lessons 2.0: What can the world learn from educational change in Finland? Teachers College Press.}

La atracción por el modelo de enseñanza finlandés afecta a tanto a académicos y administradores extranjeros del ámbito educativo, como a los propios académicos y administardores del ámbirto educativo finlandés que son invitados como asesores por gobiernos extranjeros y/o publican monografías específicas sobre el modelo finlandés de enseñanza. En este libro el reconocido experto en educación finlandesa, quien ha desempeñado puestos de responsabilidad en organismos internacionales, desgrana las características del modelo educativo finés y las claves de su éxito.

\section{Resultados}

\section{Caracterización de la muestra}

Con 290 participantes, la media de edad se sitúa en los 21 años y una desviación típica de 5 '2, lo que indica que la muestra es relativamente joven, en concordancia con el estudiantado de primero y segundo curso de las titulaciones de grado. Por su parte la Tabla 1 muestra que ocho de cada diez (el 79\%) de quienes participaron en las tertulias eran mujeres. Y la Tabla 2 que el $28^{\prime} 6 \%$ del alumnado cursaba primero de carrera y el $71 \%$ restante, segundo.

Tabla 1: Distribución por sexo

\begin{tabular}{|rl|r|r|r|r|}
\hline & & & & Porcentaje \\
& & Frecuencia & Porcentaje & Porcentaje válido & acumulado \\
\hline Válido & $\mathrm{H}$ & 59 & 20,3 & 20,3 & 20,3 \\
& $\mathrm{M}$ & 228 & 78,6 & 78,6 & 99,0 \\
& & 3 & 1,0 & 1,0 & 100,0 \\
& $\mathrm{NC}$ & 290 & 100,0 & 100,0 & \\
\hline
\end{tabular}

Tabla 2: Distribución por curso

\begin{tabular}{|rr|r|r|r|r|}
\hline & & & & $\begin{array}{c}\text { Porcentaje } \\
\text { acumulado }\end{array}$ \\
\hline Válido & Frecuencia & Porcentaje & Porcentaje válido & 28,6 \\
& 1,0 & 83 & 28,6 & 28,6 & 99,7 \\
& 2,0 & 206 & 71,0 & 71,0 & 100,0 \\
& 3,0 & 1 &, 3 &, 3 & \\
\hline & 290 & 100,0 & 100,0 & \\
\hline
\end{tabular}

Como se muestra en la Tabla 3, existió cierta variabilidad respecto a la elección de las lecturas en aquellos grupos en los que esta posibilidad se les ofreció. Los libros de Adorno y Pennac eran únicos en sus respectivos cursos (segundo curso de Sociología y Magiterio de primer curso). Por su parte los alumnos de segundo curso de Sociología pudieron elegir

(c)) EY-NC-ND 2016, Universitat Politècnica de València

Congreso In-Red (2016) 
entre Ferrer i Guardia y Freire, los de la línea en castellano, y entre el de Ravitch y Shalberg los de la línea en inglés, siendo más populares los de Freire y Shalberg respectivamente.

Tabla 3: Distribución por libro

\begin{tabular}{|c|c|c|c|c|c|}
\hline & & Frecuencia & Porcentaje & Porcentaje válido & $\begin{array}{l}\text { Porcentaje } \\
\text { acumulado }\end{array}$ \\
\hline \multirow[t]{8}{*}{ Válido } & Adorno & 31 & 10,7 & 10,7 & 10,7 \\
\hline & Ferrer i Guardia & 22 & 7,6 & 7,6 & 18,3 \\
\hline & Freire & 65 & 22,4 & 22,4 & 40,7 \\
\hline & Pennac & 83 & 28,6 & 28,6 & 69,3 \\
\hline & Ravitch & 3 & 1,0 & 1,0 & 70,3 \\
\hline & Sahlberg & 39 & 13,4 & 13,4 & 83,8 \\
\hline & Varios & 47 & 16,2 & 16,2 & 100,0 \\
\hline & Total & 290 & 100,0 & 100,0 & \\
\hline
\end{tabular}

\section{Valoración de la actividad}

Como se desprende de las puntuaciones obtenidas en las preguntas sobre la valoración de la contribución, propia y ajena, a la tertulia, tanto sobre su propia contribución como sobre la contribución de las y los otros participantes, ver Tabla 4 y Figuras 1 y 2, éstas son muy positivas superando siempre ampliamente los cuatro puntos sobre cinco de valoración media. En general existe también escasa variación entre aquellas puntuaciones en las que ven su propia contribución como más valorada (solo la escucha aparece como más valorada la propia) siendo la actitud, la comprensión del texto, las opiniones aportadas, los argumentos utilizados, el respeto por otras opiniones y la relación con otros contenidos, más valoradas las de sus compañeros y compañeras.

Tabla 4: Estadísticos descriptivos en valoración de la tertulia

\begin{tabular}{|l|r|r|r|r|r|}
\hline & $\mathrm{N}$ & Mínimo & Máximo & Media & \multicolumn{2}{|c|}{$\begin{array}{c}\text { Desviación } \\
\text { estándar }\end{array}$} \\
\hline IndAct & 290 & 2,0 & 5,0 & 4,414 &, 6969 \\
IndEsc & 290 & 2,0 & 5,0 & 4,710 &, 5381 \\
IndCom & 290 & 2,0 & 5,0 & 4,252 &, 7074 \\
IndOpi & 290 & 1,0 & 5,0 & 4,090 &, 8477 \\
IndArg & 287 & 1,0 & 5,0 & 4,073 &, 8053 \\
IndRes & 289 & 2,0 & 5,0 & 4,789 &, 4719 \\
IndRel & 287 & 2,0 & 5,0 & 4,293 &, 7513 \\
GruAct & 290 & 3,0 & 5,0 & 4,693 &, 4980
\end{tabular}




\begin{tabular}{|c|c|c|c|c|c|}
\hline GruEsc & 290 & 3,0 & 5,0 & 4,703 & ,5009 \\
\hline GruCom & 290 & 2,0 & 5,0 & 4,452 & ,6754 \\
\hline GruOpi & 290 & 1,0 & 5,0 & 4,528 & ,6233 \\
\hline GruArg & 290 & 1,0 & 5,0 & 4,534 & ,6448 \\
\hline GruRes & 290 & 3,0 & 5,0 & 4,800 & ,4721 \\
\hline GruRel & 290 & 2,0 & 5,0 & 4,483 & ,6870 \\
\hline Objeti & 288 & 2,0 & 5,0 & 4,628 &, 5700 \\
\hline Activid & 288 & 1,0 & 5,0 & 4,229 &, 8155 \\
\hline Texto & 288 & 1,0 & 5,0 & 4,420 & ,7185 \\
\hline Planif & 288 & 1,0 & 5,0 & 4,382 & ,7325 \\
\hline Profe & 288 & 2,0 & 5,0 & 4,823 & ,4647 \\
\hline N válido (por lista) & 280 & & & & \\
\hline
\end{tabular}

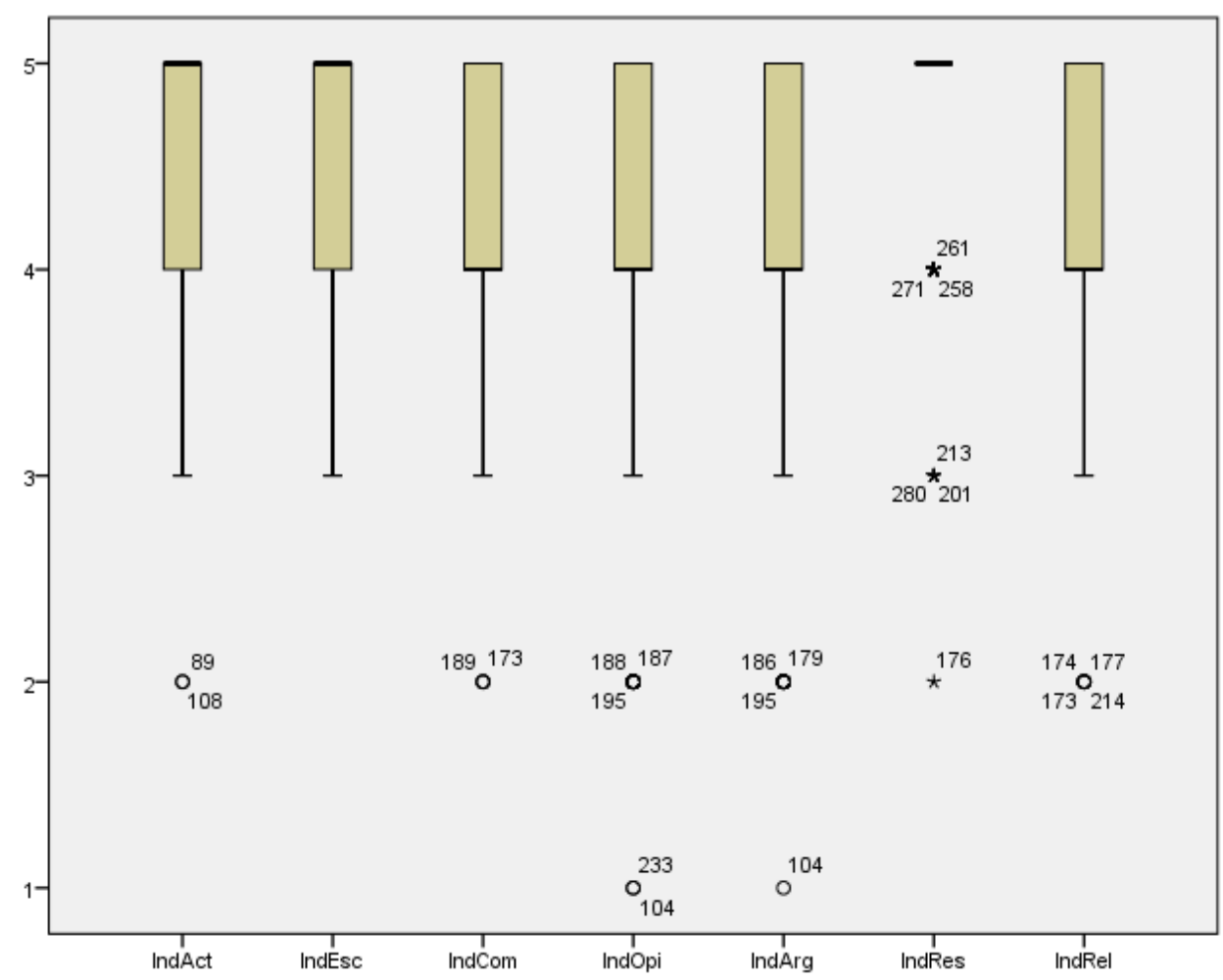

Fig. 1 Distribución de la respuesta a: ¿Cómo valoras tu contribución a la tertulia dialógica? 


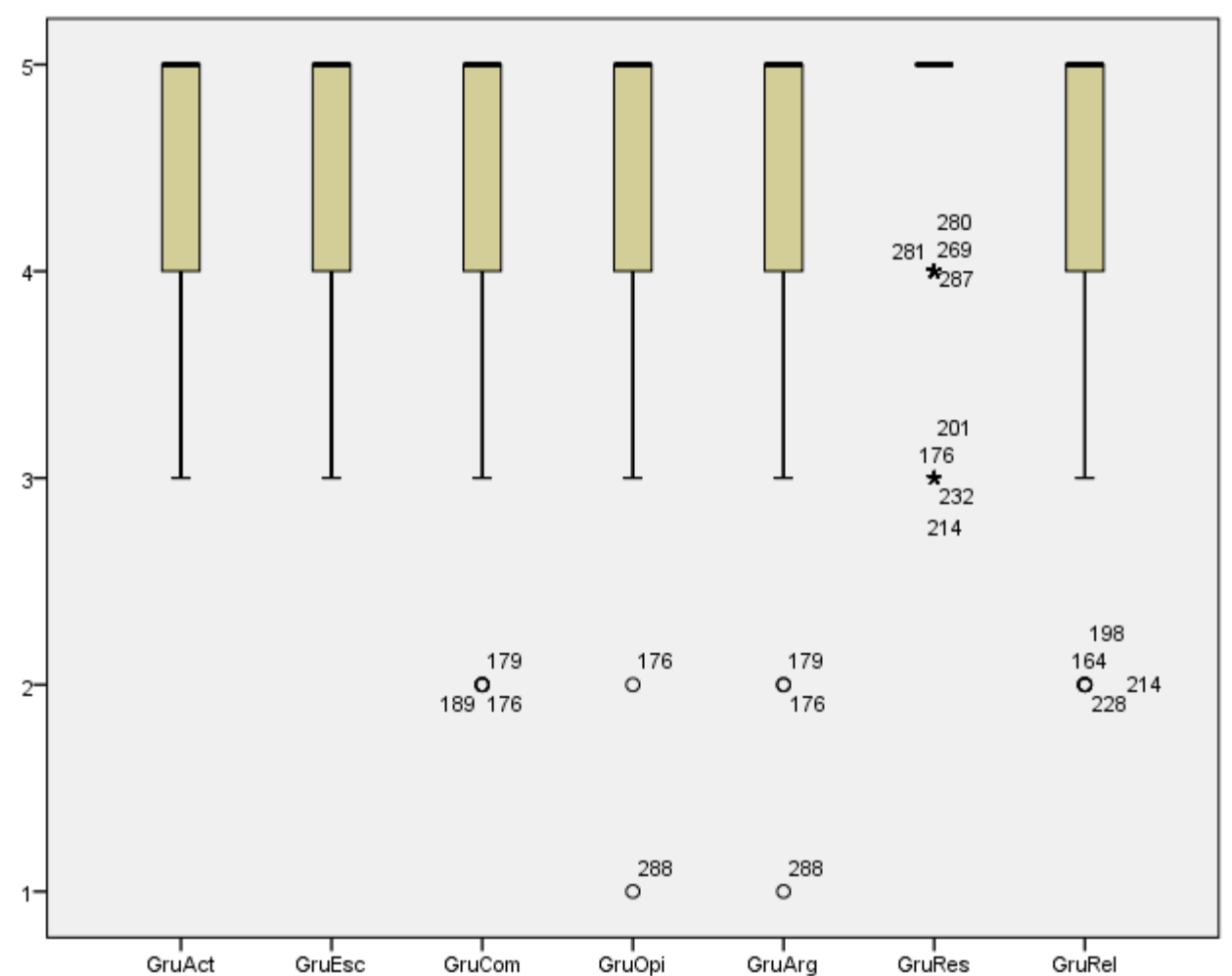

Fig. 2 Distribución de la respuesta a: ¿Cómo valoras la contribución del resto a la tertulia dialógica?

En cuanto a la valoración de la actividad, ver Tabla y Figura 4, obtiene también puntuaciones muy satisfactorias de media. Destaca la valoración de la calidad de la intervención del profesor con una valoración media de 4,8 así como los objetivos alcanzados 4,6 y la idoneidad del texto ambos con una media de 4,4. 


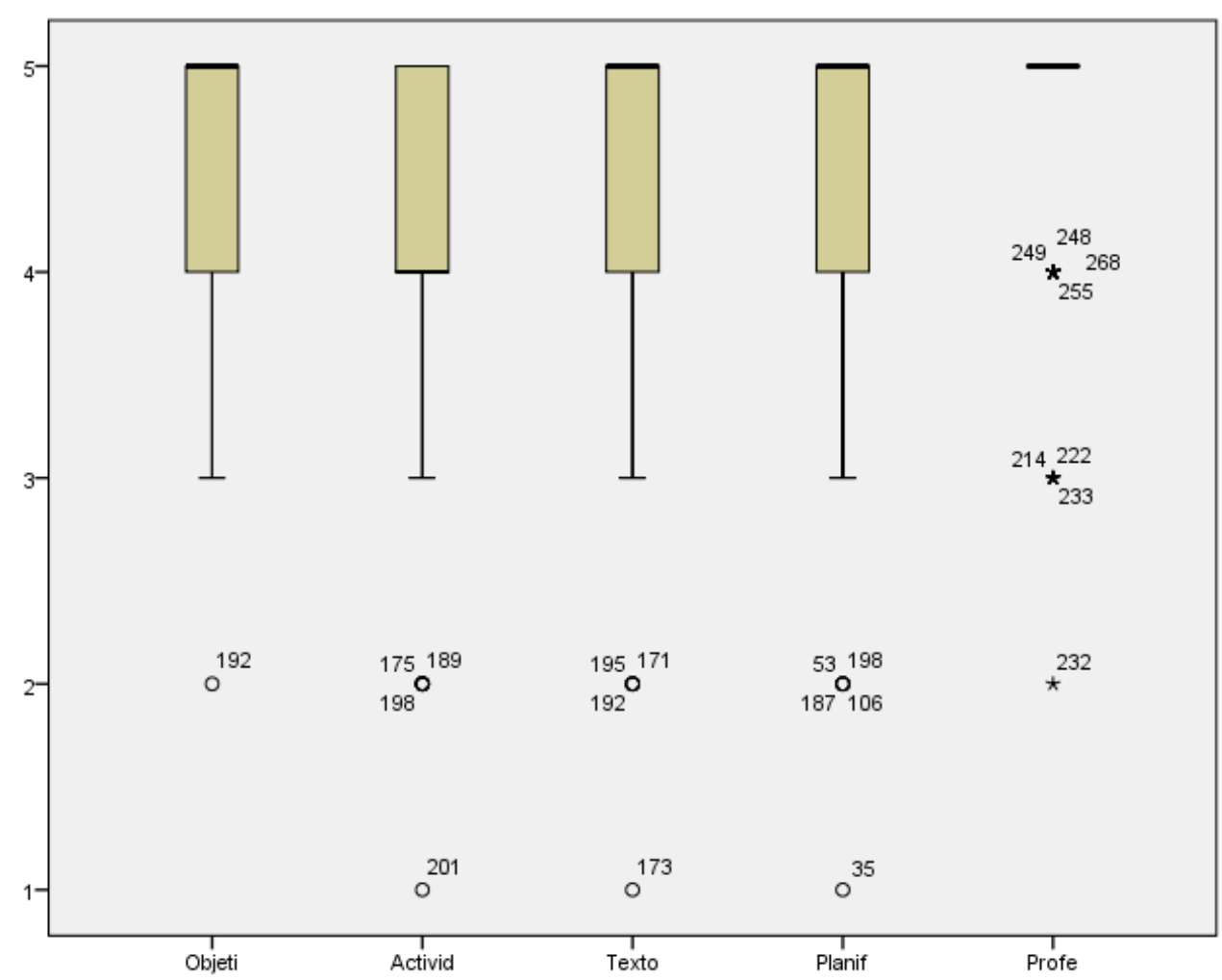

Fig. 3 Distribución de la respuesta a: ¿Cómo valoras la tertulia dialógica como actividad del curso?

\section{Conclusiones}

El proyecto TediGraMa que presentamos, de alguna manera, contribuye a actualizar dos de las ideas que inspiraron a John Dewey la puesta en marcha de una Escuela-Laboratorio, anexa a la Universidad de Chicago, hace más de cien años: la idea de experimento y la idea de creatividad. La idea de experimento se sustenta en el valor de la experimentación continua -del trabajo empírico, a partir del terreno de la realidad natural y social- como fuente de conocimiento. En este sentido la escuela misma, como la sociedad, se convierten en una suerte de laboratorio para generar ocasiones de aprendizaje. La idea de creatividad se fundamenta en la capacidad de los seres humanos para innovar -renovar y reconstruir- la sociedad a la que pertenecen con fines democráticos y emancipadores: de ahí el nombre de democracia creativa a una de sus propuestas más sugerentes. No es casual que el proyecto de Tedigrama se haya llevado a cabo en un Laboratorio de Ciencias Sociales en el seno de la Universidad de Valencia, que también ha sido creado con objetivos de progreso y mejora social, y al que cabe agradecer su colaboración para hacer posible este proyecto.

El objetivo de este trabajo ha sido presentar los resultados de una experiencia innovadora, las tertulias literarias dialógicas, llevada a cabo con alumnado de la Universitat de València, durante el curso 2015/16. El alto grado de satisfacción del alumnado con esta metodología participativa. Tanto la selección del texto como la valoración de las diferentes 
contribuciones a la tertulia (la propia, la de compañeras y compañeros e incluso la del profesor), fueron altamente valoradas. Lo son para quienes ya tenían alguna experiencia previa como para quienes se estrenaron con esta metodología. Y aunque existen aspectos de mejora relativos a la implementación de la actividad (mejor planificación de las sesiones, duración de las mismas, etc.) la conclusión es que la experiencia fue un éxito.

A pesar de la constatación de la dificultad de alguna de las obras, por su contenido y/o por su lengua, y de las condiciones en que ha tenido que ser leída (no es habitual leer obras enteras en el ámbito universitario), las grabaciones muestran el interés y el éxito de la práctica no solamente en relación al contenido de los libros, sino fundamentalmente a la consideración unánime que este tipo de pedagogía debería ser realizada en el práctica docente habitual, sustituyendo a las lecciones magistrales del profesorado. De algún modo la mayoría ha manifestado que el libro era muy bueno y que la experiencia duraba muy poco, con la que la experiencia ha sido satisfactoria, pero limitada.

Por tanto podemos afirmar que la experiencia indica que las tertulias dialógicas fomentan la reflexión en grupo, no solo de los contenidos de la lectura propuesta y de los contenidos teóricos, sino de las propias vivencias en etapas anteriores en tanto que alumnado de enseñanzas preuniversitarias, como también de las vivencias acaecidas en el contexto del Practicum I. En consecuencia la valoración del alumnado en cuanto a la actividad es altamente satisfactoria hayan o no tenido experiencias previas con esta metodología. En conclusión, la experiencia pone de manifiesto la necesidad de seguir innovando y enriqueciendo las metodologías docentes que aplicamos en el aula.

\section{Referencias}

ANAYA, G. (1977) Una ruptura en la enseñanza. Valencia: Fernando Torres.

ARDOINO, J. (1980) Perspectiva politica de la educación. Madrid: Narcea.

BAIN. K. (2007) Lo que hacen los mejores profesores universitarios. Valencia: PUV.

BAIN. K. (2014) Lo que hacen los mejores estudiantes de universidad. Valencia: PUV.

CHOMSKY, N. (2010) La (des)educación. Barcelona: Crítica.

CORDON, F. (1982) La función de la ciencia en la sociedad. Barcelona: Anthropos.

DUBET, F. (2013) El declive de la institución. Barcelona: Gedisa.

FREIRE, P. (2012). Cartas a quien pretende enseñar. Madrid: Biblioteca Nueva.

FREIRE, P. (2009) La educación como práctica de la libertad. Madrid: SXXI.

GIROUX, H. (1990) Los profesores como intelectuales. Barcelona: Paidós.

MORIN, E. (2001) Los siete saberes necesarios para la educación del futuro. Barcelona: Paidós.

MARTÍN, E. (2010) La escuela sin funciones. Barcelona: Bellaterra.

REQUERO, M. I. M., y YUSTE, A. J. (2013). "Las tertulias literarias dialógicas, un desafío para la creatividad y la convivencia" en Creatividad y sociedad: revista de la Asociación para la Creatividad vol. 21, p. 8-21.

(cc) BY-NC-ND 2016, Universitat Politècnica de València 
WAGENSBERG, J. (2007) El gozo intelectual. Barcelona: Tusquets.

(c)) EY-NC-ND 2016, Universitat Politècnica de València

Congreso In-Red (2016) 
ANEXO 1

¿Cómo valoras tu contribución a la tertulia dialógica?

\begin{tabular}{|c|c|c|c|c|c|c|c|}
\hline Actitud & Negativa & 1 & 2 & 3 & 4 & 5 & Positiva \\
\hline Escucha & Pasiva & 1 & 2 & 3 & 4 & 5 & Activa \\
\hline Comprensión del texto & Pobre & 1 & 2 & 3 & 4 & 5 & Buena \\
\hline Opiniones aportadas & Irrelevantes & 1 & 2 & 3 & 4 & 5 & Relevantes \\
\hline Argumentos utilizados & Pobres & 1 & 2 & 3 & 4 & 5 & Ricos \\
\hline Respeto por otras opiniones & Bajo & 1 & 2 & 3 & 4 & 5 & Alto \\
\hline Relación con otros contenidos & Desconectada & 1 & 2 & 3 & 4 & 5 & Conectada \\
\hline
\end{tabular}

¿Cómo valoras la contribución del resto a la tertulia dialógica?

Actitud

Escucha activa

Comprensión del texto

Opiniones aportadas

Argumentos utilizados

Respeto por otras opiniones

Relación con otros contenidos
Negativa

Pasiva

Pobre

Irrelevantes

Pobres

Bajo

Desconectada

\begin{tabular}{|c|c|c|c|c|c|}
\hline 1 & 2 & 3 & 4 & 5 & Positiva \\
\hline 1 & 2 & 3 & 4 & 5 & Activa \\
\hline 1 & 2 & 3 & 4 & 5 & Buena \\
\hline 1 & 2 & 3 & 4 & 5 & Relevantes \\
\hline 1 & 2 & 3 & 4 & 5 & Ricos \\
\hline 1 & 2 & 3 & 4 & 5 & Alto \\
\hline 1 & 2 & 3 & 4 & 5 & Conectada \\
\hline
\end{tabular}

¿Cómo valoras la tertulia dialógica como actividad del curso?

Objetivos alcanzados

Realización de la actividad

Idoneidad del texto

Adecuación de la planificación

Calidad de la intervención del profesor
No alcanzados

Difícil

Poco idóneo

Mala

Pobre

\begin{tabular}{|l|l|l|l|l|l}
\hline 1 & 2 & 3 & 4 & 5 & Alcanzados \\
\hline 1 & 2 & 3 & 4 & 5 & Fácil \\
\hline 1 & 2 & 3 & 4 & 5 & Idóneo \\
\hline 1 & 2 & 3 & 4 & 5 & Buena \\
\hline 1 & 2 & 3 & 4 & 5 & Rica \\
\end{tabular}

Problemas observados:

Propuestas de mejora:

(cc) EY-NC-ND 2016, Universitat Politècnica de València 
¿Habías participado en alguna tertulia antes?

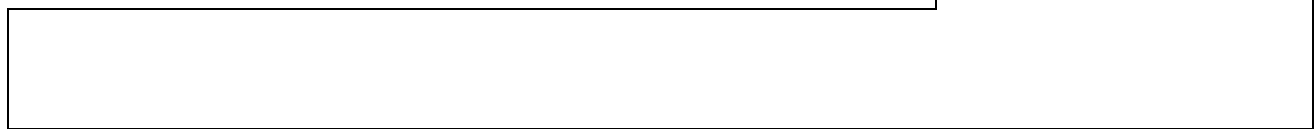

Edad:

Sexo:

Curso:

(cc) EY-NC-ND 2016, Universitat Politècnica de València

Congreso In-Red (2016) 